\title{
Pre-Operative Factors Affecting Resectability of Giant Intracranial Meningiomas
}

\author{
Alfredo Quiñones-Hinojosa, Tania Kaprealian, Kaisorn L. Chaichana, \\ Nader Sanai, Andrew T. Parsa, Mitchel S. Berger, Michael W. McDermott
}

\begin{abstract}
Objective: Larger intracranial tumors require extended operating times and may be associated with increased perioperative complications. There are few reports describing the experience of resecting large meningiomas $\geq 5 \mathrm{~cm}$ in a variety of locations. As a group, it remains largely unknown whether these relatively rare lesions are amenable to radical resection, and what factors influence their resectability. Methods: Sixty-seven patients undergoing surgery for a large intracranial meningioma $(\geq 5 \mathrm{~cm}$ in the longest dimension) between 1998 and 2004 were retrospectively reviewed. The surgeries were performed at a single institution University of California at San Francisco. Predictors of resectability were assessed via multivariate logistical regression analysis. Results: Thirty-nine (58\%) patients underwent gross total resection (GTR) (Simpson grades I/II). There were no cases of perioperative mortality. At last follow-up, symptoms improved in 39 (58\%) patients, remained unchanged in 20 (30\%), and were aggravated in 8 $(12 \%)$. In the multivariate model for all large meningiomas, age $>45$ years [OR(95\%CI);0.127 $(0.026-0.616)$, $\mathrm{p}=0.01]$ and superior sagittal sinus involvement [OR(95\%CI);0.160 (0.026-0.976),p=0.05] were negative predictors of GTR, while preoperative embolization [OR(95\%CI);8.087(1.719-38.044), $\mathrm{p}=0.008]$ was positively associated with GTR. For only supratentorial meningiomas, superior sagittal sinus involvement [OR $(95 \% \mathrm{CI}) ; 0.077(0.010-0.571), \mathrm{p}=0.01]$ and preoperative embolization [OR(95\%CI);10.492(1.96156.135),p=0.006] were independently associated with GTR. Conclusions: This study evaluated a subset of large intracranial meningiomas $\geq 5 \mathrm{~cm}$. The results indicate that GTR can be achieved in the majority of cases with limited morbidity and mortality, where symptoms will likely improve and recurrences seldom occur. This study may provide useful insights for patients undergoing surgery for large intracranial meningiomas.
\end{abstract}

RÉSUMÉ: Facteurs préopératoires affectant la résécabilité des méningiomes intracrâniens géants. Objectif : La résection des grosses tumeurs intracrâniennes nécessite un temps opératoire prolongé et peut être associée à une augmentation des complications périopératoires. Il existe peu d'articles décrivant l'expérience acquise dans la résection de gros méningiomes de $5 \mathrm{~cm}$ ou plus situés dans différents endroits. On ne sait pas encore vraiment si ce type de lésion relativement rare est traitable par résection radicale et quels sont les facteurs qui influencent leur résécabilité. Méthodes : Nous avons révisé les dossiers de 67 patients qui ont subi la résection d'un gros méningiome intracrânien ( $\geq 5 \mathrm{~cm}$ dans sa plus grande dimension) entre 1998 et 2004. La chirurgie a été effectuée dans une seule institution (UCSF). Les éléments qui prédisaient la résécabilité ont été évalués par analyse de régression logistique multivariée. Résultats : Trente-neuf (58\%) des patients ont subi une résection totale fruste (RTF) (Simpson grades I/II), sans mortalité périopératoire. Au dernier suivi, les symptômes s'étaient améliorés chez 39 patients (58\%); ils étaient inchangés chez 20 (30\%) et s'étaient aggravés chez 8 (12\%). À l'analyse multivariée incluant tous les gros méningiomes, l'âge inférieur à 45 ans (RC 0,127 et IC à $95 \%$ de 0,026 à 0,$616 ; \mathrm{p}=0,01)$ et l'atteinte du sinus sagittal supérieur (RC 0,160 et IC à $95 \%$ de 0,026 à 0,$976 ; \mathrm{p}=0,05)$ prédisaient négativement une RTF alors qu'il existait une association positive entre l'embolisation préopératoire et la RTF (RC 8,087 et IC à 95\% de 1,719 à 38,044; $\mathrm{p}=0,008)$. Quant aux méningiomes supratentoriels, l'atteinte du sinus sagittal supérieur (RC 0,077 et IC à $95 \%$ de 0,010 à 0,$571 ; p=0,01)$ et l'embolisation préopératoire (RC 10, 492 et IC à $95 \%$ de 1,961 à 56,135; p = 0,006) étaient associées de façon indépendante à la RTF. Conclusions : Cette étude a évalué un sousgroupe de gros méningiomes intracrâniens de $5 \mathrm{~cm}$ ou plus. Les résultats indiquent que la RTF peut être effectuée dans la majorité des cas et comporte une morbidité et une mortalité limitées. Les symptômes s'améliorent et les récidives sont rares. Cette étude peut fournir des renseignements utiles pour les patients qui subissent une chirurgie pour un gros méningiome intracrânien.

Can. J. Neurol. Sci. 2009; 36: 623-630

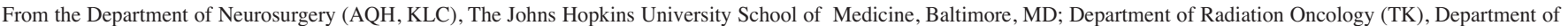
Neurological Surgery (NS, ATP, MSB, MWM), University of California at San Francisco, San Francisco, CA, USA.

Received February 10, 2009. Final Revisions Submitted May 19, 2009.

Correspondence to: Alfredo Quiñones-Hinojosa, The Johns Hopkins Hospital, Department of Neurosurgery, Johns Hopkins University, CRB II, 1550 Orleans Street, Room 253, Baltimore, MD, 21231, USA. 
Meningiomas are generally benign, slow growing tumors that comprise approximately $20 \%$ of all intracranial tumors ${ }^{1,2}$. As a result, signs and symptoms are often subtle, allowing these tumors to reach large sizes with minimal neurological deficits. However, advances in neuro-imaging have allowed for the early detection of these often initially small and asymptomatic tumors $^{3}$. Therefore, large meningiomas $>5$ centimeters $(\mathrm{cm})$ in a variety of locations are rarely reported, and the clinical presentation, management, and surgical outcomes are largely unstudied. In fact, the literature is primarily limited to small case series (<six patients) and case reports ${ }^{4-7}$. As a group, it remains largely unknown whether these relatively rare lesions are amenable to radical resection, and what factors influence their resectability.

We provide a comprehensive description of the presentation, surgical management, and factors associated with the resectability of large intracranial meningiomas in 67 patients. These meningiomas all were $\geq 5 \mathrm{~cm}$ in the longest dimension, and were operated on at the University of California at San Francisco (UCSF). An understanding of factors that may guide resectability may therefore maximize the chances for excellent outcomes following surgery of these relatively rare tumors.

\section{Materials ANd Methods}

\section{Subjects}

Sixty-seven patients with intracranial meningiomas $\geq 5 \mathrm{~cm}$ in the longest dimension were retrospectively reviewed. These patients were operated on at the UCSF between April 1998 and January 2004. Information recorded for each patient included demographics, clinical presentation, co-morbidities, radiographic findings, intra-operative recordings, pathological findings, and postoperative neurological function. Extent of resection was determined by postoperative magnetic resonance imaging (MRI) in combination with intraoperative findings most specifically for the Simpson grades I (complete removal including resection of underlying bone and associated dura) and II (complete removal + coagulation of dural attachment) cases where the intraoperative observations of the surgeon are necessary. Gross total resection (GTR) was defined as being Simpson grade I or II, where the tumor was macroscopically removed with no evidence of residual tumor on post-operative neuro-imaging and the dural attachment was either removed or coagulated $^{8}$. Simpson grade III was notably excluded from the definition of GTR in order to reflect those tumors with the smallest chance of recurrence ${ }^{8}$. Peri-operative mortality was defined as death within 30 days of surgery. Postoperatively, patients obtained an MRI one to three days after surgery. In general, imaging scans were done once a year for patients who had subtotal resection (GTR) and low grade tumors, every six months for GTR of atypical meningiomas, every four months for STR of tumors, and every three months for malignant meningiomas.

\section{Operative Techniques}

Prior to surgery, lesions in all patients were evaluated using MRIand cerebral angiography. For MRI, patients underwent T1weighted imaging, T2-weighted imaging, and contrast enhancement with gadolinium. Cerebral angiography included injection of the left subclavian artery, bilateral internal and external carotid arteries, and bilateral vertebral arteries. The results of the angiography were useful in planning the surgery, evaluating the patencies of the venous sinuses, and understanding the vascular supply and anatomy of the tumor before tumor debulking.

The majority of these tumors $(66 \%)$ were selected for preoperative angiography with embolization. The indications may include size and location (for instance proximity to the superior sagittal sinus). Studies have shown that angiography with embolization preoperatively minimizes intraoperative blood loss and assists the surgical resection ${ }^{9,10}$. Furthermore, we have previously shown that in order to further decrease blood loss, surgical resection of these embolized meningiomas should be delayed for more than 24 hours post-embolization ${ }^{9}$. In our limited experience, we feel that embolization has been useful in planning the surgery and to pre-operatively anticipate and understand the vascular supply and anatomy of the tumor. Furthermore, surgical navigation systems are recommended for these surgeries if the surgeon considers it appropriate. We believe the use of these systems during tumor debulking assists with the efficiency and confidence of tumor removal.

Patient positioning depends on the surgeon's preference and the patient's body habitus. In cases where flexion of the neck is required for positioning (i.e. patients with tumors in the posterior fossa and/or in the prone position) we recommend the use of armored endotracheal tubes to avoid kinking and obstruction with positioning, as well as softening of the plastic tube as the operation proceeds. An external ventricular drain, which can be placed with the aid of the surgical navigation system, should be also considered for patients with large tumors. We advocate large incisions with extensive bone work since this extra bone removal may reduce resistance against retraction of the brain. Routinely, the dura is opened beyond the lateral margins of the tumor. The next step depends on the status of the sinuses as assessed by angiography. If the sinuses are patent, the sinuses are typically preserved, unless the tumor involves the anterior third of the superior sagittal sinus. However, if the sinuses are occluded, they are routinely suture-ligated at the margin of the tumor. Reconstruction of the sinus, as recently reported by Sindou et $\mathrm{al}^{11}$, was not routinely practiced.

The brain is invariably gently retracted for hours, intermittently and alternately, as the resection proceeds, and the pial surfaces are covered with rubber dams to avoid sticking of cottonoids or telfa that are left on for hours. In cases of significant cerebral swelling at the conclusion of the tumor removal, the bone flap can be left off and the patient positioned safely side-to-side until the bone can be replaced. In cases that last over 12 hours, our practice has been to leave the patient intubated overnight, and the external ventricular drain is used for pressure monitoring and intracranial pressure management.

Large tumors in the anterior cranial fossa arise from the olfactory groove and planum region. While many of these tumors cannot be embolized due to pial or ethmoid supply, dissection of the ethmoid arteries within the medial wall of the orbit on exposure for ligation is an option. Generally extended skull flaps are best and bifrontal craniotomies with supraorbital osteotomies provide great exposure of the tumor base without much brain retraction so the blood supply can be interrupted 
early. In older patients we routinely create a bi-partite frontal flap, removing a right frontal bone flap short of the midline first, and then under direct vision dissecting the dura across the midline superior sagittal sinus to the left before removing the second left sided flap. These can be reconnected with counter sunk plates using hydroxappetite to fill in depressions.

Large tumors in the middle cranial fossa are mainly found around the clinoid, medial, inner and outer third of the sphenoid wing. We prefer using coronal scalp incisions so that there is no undo prolonged tension on the skin flap as might be created by trying to use a unilateral curvilinear incision. Surgeons should be careful to avoid placing draping towels above the supra-orbital margin as these add to the pressure on the base of turned down scalp flaps and to the underlying orbit. Extradural opening of the optic canal, when possible, provides the quickest way to identify the optic nerve at the base of large tumors. If the cavernous sinus is involved we recommend a microsurgical approach with an exploration and, in young patients, an attempt to resect the tumors completely if possible.

Large tumors around the convexity can be adherent to the pial surface. When there is considerable mass effect or edema it is often helpful to open the dura in a cruciate manner directly over the tumor and debulk it centrally before extending the dural openings to the margin which exposes normal cortex. In this way reduction of mass effect may limit herniation of normal tissue at the margins of the dural opening. Once the normal adjacent cortex is exposed additional relaxation can be accomplished by opening the arachnoid over prominent sulci or the Sylvian fissure. Care must be taken to preserve cortical draining veins otherwise technical success with tumor removal will be tarnished by post-operative venous infarction. Large dural defects can frequently be covered with pericranium harvested from under the scalp flap or adjacent areas. When harvesting this pericranium as a free tissue graft it is best to leave behind the loose areolar tissue which can swell in-situ and act as a mass lesion. Even for large tumors it is best to attempt to remove a margin of normal dura around the tumor attachments to reduce the chance of marginal recurrence.

For both parasagittal and falx meningiomas we use a bipartite bone flap, opening on the side where the largest tumor mass is located with burr holes lateral to the midline and then, once the first flap is off, dissecting across the midline to the opposite side to remove the second component. This gives the surgeon the opportunity to explore both sides of a large falx meningioma and may allow dissection and interruption of anterior falx artery or pial anterior cerebral artery supply. The aim with surgery in this region should be preservation of all parasagittal cortical draining veins. However, smaller veins not thought to be the dominant superior anastomotic vein may have to be sacrificed for dissection and tumor removal, acknowledging the risk of subsequent infarction. In our practice the superior sagittal sinus (SSS) attachments are dissected from the outer leaf of the dura and the inner leaf coagulated. We do not routinely excise and reconstruct the lateral wall. In cases where there is proven occlusion on the SSS by venous phase of a preo-operative angiogram then excision of the sinus is an option.

\section{Statistical Analysis}

To identify associations with GTR of all large intracranial meningiomas, univariate logistical regression analysis (JMP6,
SAS, 2006) was performed to assess all radiographic, preoperative, operative, and pathologic variables associated with post-operative extent of resection. All variables associated with post-operative GTR $(\mathrm{p}<0.1)$ for all large intracranial meningiomas in the univariate analysis were included in a multivariate logistical regression model (JMP6, SAS, 2006). Percentages were compared via Chi-squared and Fisher-exact tests where appropriate. For inter-group comparison, the student's t-test was used for parametric data and the ManWhitney U test for non-parametric data. Summary data were given as mean \pm standard deviation for parametric data and median [interquartile range (IQR)] for non-parametric data.

\section{RESULTS \\ Patient Characteristics}

Table 1 summarizes the patient characteristics. Sixty-seven patients underwent large meningioma $(\geq 5 \mathrm{~cm})$ resection during the reviewed period. Forty-five patients $(67 \%)$ were female, and the mean age at surgery was $52.7 \pm 15.2$ years. The median [IQR] duration of symptoms prior to diagnosis was 6 [range, 212] months. The most common presenting symptoms were headache, visual deterioration, and mental disturbance. Other symptoms included motor weakness, sensory disturbance, ataxia, seizures, and aphasia.

The average size of the tumor by neuroimaging was $6.3 \pm 1.3$ $\mathrm{cm}$, with an average volume of $164.8 \pm 90.0 \mathrm{~cm}^{3}$. Fifty-eight (87\%) meningiomas were supratentorial and $9(13 \%)$ were infratentorial. The supratentorial locations were along the cortical convexity, falx, parasgittal region, olfactory groove, sphenoid wing, and suprasella (planum sphenoidale, tuberculum sellae). The infratentorial locations were either along the cerebellar hemispheres or cerebellopontine angle (CPA). Superior sagittal sinus and cavernous sinus involvement were noted in $13 \%$ and $7 \%$ of patients, respectively, where involvement was defined as encasing, displacing, or invading named structures.

Of the 67 patients in this series, $8(12 \%)$ had undergone prior resection, 7 (10\%) prior radiation therapy, and $45(67 \%)$ preoperative embolization. Among those who underwent embolization, the tumor involved the convexity in $15(33 \%)$, parasagittal region in $10(22 \%)$, sphenoid wing in $8(18 \%)$, falcine in $5(11 \%)$, suprasella in $3(7 \%)$, olfactory groove in 2 (4\%), CPA in $1(2 \%)$, and cerebellar hemispheres in $1(2 \%)$. Pathologically, $49(73 \%)$ were World Health Organization (WHO) grade I; 13 (19\%) WHO grade II, and 5 (7\%) WHO grade III.

\section{Outcome}

Table 2 outlines the outcomes following large meningioma $(\geq 5 \mathrm{~cm}$ ) resection. Thirty-nine $(58 \%)$ patients underwent GTR. Thirty-three (49\%) were Simpson Grade I, 6 (9\%) Simpson Grade II, 12 (18\%) Simpson Grade III, and 16 (24\%) Simpson Grade IV. The median blood loss was 800 [500-1300] milliliters, and the median operating time was 10 [6.5-13.5] hours. There were no cases $(0 \%)$ of peri-operative mortality. Following surgery, there were $11(16 \%)$ total complications. The main complications included new-onset seizures, venous infarcts, and cerebrospinal fluid leak requiring operative repair. The median length of hospital stay was 6 [4-9] days. At a median [IQR] of 17 
Table 1: Summary of characteristics in 68 patients with large intracranial meningiomas

\begin{tabular}{|c|c|}
\hline Characteristics & No. of Patients (\%) \\
\hline $\begin{array}{l}\text { Age } \\
<45 \text { years } \\
45-60 \text { years } \\
>60 \text { years }\end{array}$ & $\begin{array}{l}24(36 \%) \\
22(33 \%) \\
21(31 \%)\end{array}$ \\
\hline $\begin{array}{l}\text { Gender } \\
\text { Female }\end{array}$ & $45(67 \%)$ \\
\hline $\begin{array}{l}\text { Presenting symptoms } \\
\text { Headache } \\
\text { Visual deterioration } \\
\text { Mental disturbance } \\
\text { Motor weakness } \\
\text { Ataxia } \\
\text { Sensory disturbance } \\
\text { Seizures } \\
\text { Aphasia }\end{array}$ & $\begin{array}{c}28(42 \%) \\
23(34 \%) \\
22(33 \%) \\
12(18 \%) \\
11(16 \%) \\
7(10 \%) \\
9(13 \%) \\
3(4 \%)\end{array}$ \\
\hline $\begin{array}{l}\text { Prior treatment } \\
\text { Prior resection } \\
\text { Radiation treatment } \\
\text { Preoperative embolization }\end{array}$ & $\begin{array}{c}8(12 \%) \\
7(10 \%) \\
45(67 \%) \\
\end{array}$ \\
\hline $\begin{array}{l}\text { Radiographics: } \\
\text { Size: } \\
5-6 \mathrm{~cm} \\
6-7 \mathrm{~cm} \\
7-8 \mathrm{~cm} \\
>8 \mathrm{~cm} \\
\text { Location: } \\
\text { Supratentorial } \\
\text { Convexity } \\
\text { Parasagittal } \\
\text { Falx } \\
\text { Sphenoid wing } \\
\text { Suprasellar } \\
\text { Olfactory groove } \\
\text { Infratentorial } \\
\text { Clivus/Foramen Magnum } \\
\text { Cerebellopontine angle } \\
\text { Cerebellum } \\
\text { Superior sagittal sinus invasion } \\
\text { Cavernous sinus invasion } \\
\text { Hyperostosis } \\
\text { En plaque }\end{array}$ & $\begin{array}{c}32(48 \%) \\
22(33 \%) \\
5(7 \%) \\
8(12 \%) \\
\\
58(87 \%) \\
17(25 \%) \\
11(16 \%) \\
6(9 \%) \\
11(16 \%) \\
7(10 \%) \\
6(9 \%) \\
9(13 \%) \\
5(7 \%) \\
2(3 \%) \\
2(3 \%) \\
9(13 \%) \\
5(7 \%) \\
12(18 \%) \\
1(1 \%) \\
\end{array}$ \\
\hline $\begin{array}{l}\text { Pathology } \\
\text { WHO grade I } \\
\text { WHO grade II } \\
\text { WHO grade III }\end{array}$ & $\begin{array}{c}49(73 \%) \\
13(19 \%) \\
5(7 \%)\end{array}$ \\
\hline
\end{tabular}

[5-26] months, symptoms improved in 39 (58\%) patients, remained unchanged in $20(30 \%)$, and were aggravated in 8 $(12 \%)$. We left the bone flap off in one patient due to intraoperative swelling.

\section{Predictors of Post-Operative Extent of Resection in All Large Intracranial Meningiomas}

Univariate analysis associations $(\mathrm{p}<0.1)$ with GTR for all intracranial meningiomas included: age greater than 45 years,
Table 2: Summary of operative outcomes in 68 patients with large intracranial meningiomas at last follow-up

\begin{tabular}{l|c}
\hline \multicolumn{1}{c|}{ Outcome } & No. of Patients (\%) \\
\hline Gross total resection (Simpson Grade I and II) & $39(58 \%)$ \\
Simpson Grade I (complete removal including & \\
resection of underlying bone and associated dura) & $33(49 \%)$ \\
Simpson Grade II (complete removal + & $6(9 \%)$ \\
coagulation of dural attachment) & $12(18 \%)$ \\
Simpson Grade III (complete removal w/o & $16(24 \%)$ \\
resection of dura or coagulation) & \\
Simpson Grade IV (subtotal resection) & $39(58 \%)$ \\
\hline Symptoms: & $20(30 \%)$ \\
Improved & $8(12 \%)$ \\
Unchanged & $1(1 \%)$ \\
Worsened & $3(4 \%)$ \\
\hline Complications & $2(3 \%)$ \\
Wound infection & \\
Obstructive hydrocephalus & \\
\hline CSeizures & $1 \%)$ \\
\hline Pseudomeningocele & \\
\hline
\end{tabular}

superior sagittal sinus involvement, cavernous sinus involvement, prior resection, and preoperative embolization (Table 3). No other clinical, imaging, operative, or pathologic variables were found to be associated with GTR.

In the multivariate model, after adjusting for each of these associated variables, age $>45$ years [OR(95\%CI); 0.127 (0.0260.616), $\mathrm{p}=0.01]$, superior sagittal sinus involvement [OR(95\%CI); $0.160(0.026-0.976), \mathrm{p}=0.05]$, and preoperative embolization [OR(95\%CI); 8.087 (1.719-38.044), p=0.008] were found to be independently associated with GTR (Table 4). Age $>45$ years made it approximately eight times less likely that GTR would be achieved. Twenty-one of $43(48 \%)$ patients older than 45 years achieved GTR, as compared to 18 of $24(75 \%)$ patients younger than 45 years. Additionally, superior sagittal sinus involvement made it approximately six times less likely that GTR would be achieved. Three of nine (33\%) patients with superior sagittal sinus involvement achieved GTR, as compared to 36 of $58(62 \%)$ patients without superior sagittal sinus involvement. Furthermore, the use of pre-operative embolization made it eight times more likely that GTR would be achieved. Thirty-two of $45(71 \%)$ with pre-operative embolization achieved GTR, as compared to 7 of $22(32 \%)$ who were not preoperatively embolized. The embolization rates were $88 \%(15 / 17)$ for convexity meningiomas, $91 \%$ (10/11) for parasagittal meningiomas, $73 \%(8 / 11)$ for sphenoid wing meningiomas, $83 \%$ $(5 / 6)$ for falx meningiomas, $33 \%(2 / 6)$ for olfactory groove 
meningiomas, and $43 \%$ (3/7) for suprasellar meningiomas. Additionally, one (50\%) CPA and one (50\%) cerebellar meningioma were successfully embolized. Interestingly, cavernous sinus involvement and prior meningioma resection trended towards, but did not reach statistical significance.

\section{Predictors of Post-Operative Extent of Resection in Large Supratentorial Meningiomas}

In the multivariate model, after adjusting for each of these associated variables, superior sagittal sinus involvement [OR(95\%CI); $0.077(0.010-0.571), \mathrm{p}=0.01]$ and preoperative embolization [OR(95\%CI); 10.492 (1.961-56.135), $\mathrm{p}=0.006$ ] were independently associated with extent of resection (Table 5).

Table 3: Univariate associations with gross total resection following resection of all large intracranial meningiomas

\begin{tabular}{|c|c|c|}
\hline \multirow[b]{2}{*}{ Variable } & \multicolumn{2}{|c|}{ Univariate } \\
\hline & Odds Ratio (95\%CI) & p-value \\
\hline Age $>45$ & $0.318(0.106-0.956)$ & 0.04 \\
\hline Female & $0.947(0.336-2.668)$ & 0.92 \\
\hline Pre-op radiation & $0.952(0.196-4.635)$ & 0.95 \\
\hline $\begin{array}{l}\text { Pre-operative symptoms: } \\
\text { Duration of symptoms } \\
\text { Headache } \\
\text { Mental status change } \\
\text { Seizure } \\
\text { Visual deterioration } \\
\text { Motor weakness } \\
\text { Sensory } \\
\text { Ataxia }\end{array}$ & $\begin{array}{l}0.995(0.935-1.060) \\
1.457(0.534-3.974) \\
0.999(0.353-2.832) \\
1.455(0.330-6.404) \\
0.491(0.175-1.377) \\
0.963(0.270-3.426) \\
0.914(0.187-4.459) \\
0.800(0.217-2.946)\end{array}$ & $\begin{array}{l}0.88 \\
0.46 \\
0.99 \\
0.62 \\
0.18 \\
0.95 \\
0.91 \\
0.74\end{array}$ \\
\hline \multicolumn{3}{|l|}{ Radiographics: } \\
\hline $\begin{array}{l}\text { Diameter } \\
\text { Volume }\end{array}$ & $\begin{array}{l}0.742(0.505-1.091) \\
0.998(0.993-1.004)\end{array}$ & $\begin{array}{l}0.13 \\
0.54\end{array}$ \\
\hline \multicolumn{3}{|l|}{ Location: } \\
\hline Olfactory & $0.694(0.129-3.725)$ & 0.67 \\
\hline Suprasellar & $0.952(0.196-4.635)$ & 0.95 \\
\hline Sphenoid wing & $0.440(0.124-1.571)$ & 0.21 \\
\hline Convexity & $2.044(0.627-6.668)$ & 0.24 \\
\hline Cerebellopontine angle & $0.711(0.043-11.865)$ & 0.81 \\
\hline Hyperostosis & $0.963(0.270-3.426)$ & 0.95 \\
\hline En plaque & $1.000(0.999-1.001)$ & 0.98 \\
\hline Mass effect & $1.925(0.566-6.545)$ & 0.29 \\
\hline Cysts & $0.667(0.124-3.583)$ & 0.64 \\
\hline Edema & $2.449(0.843-7.114)$ & 0.11 \\
\hline \multicolumn{3}{|l|}{ Invasion of: } \\
\hline Superior sagittal sinus & $0.292(0.066-1.290)$ & 0.10 \\
\hline Cavernous sinus & $0.151(0.016-1.438)$ & 0.10 \\
\hline Transverse sinus & $1.000(0.999-1.001)$ & 0.98 \\
\hline \multicolumn{3}{|l|}{ Operative: } \\
\hline Prior resection & $0.198(0.037-1.069)$ & 0.06 \\
\hline Preoperative embolization & $5.275(1.748-15.921)$ & 0.003 \\
\hline Hydrocephalus & $0.667(0.124-3.583)$ & 0.64 \\
\hline \multicolumn{2}{|l|}{ Pathology (WHO } & 0.79 \\
\hline Grade I & $0.545(0.161-1.848)$ & 0.33 \\
\hline Grade II & $3.086(0.326-29.220)$ & 0.33 \\
\hline Grade III & & \\
\hline
\end{tabular}

Table 4: Multivariate associations with gross total resection following resection of all large supratentorial meningiomas

\begin{tabular}{l|c|c}
\hline & \multicolumn{2}{|c}{ Multivariate } \\
\hline Variable & $\begin{array}{c}\text { Odds Ratio } \\
(\mathbf{9 5 \%} \% \mathbf{C})\end{array}$ & p-value \\
\hline Age $>45$ & $0.127(0.026-0.616)$ & $\mathbf{0 . 0 1}$ \\
\hline Superior sagittal & $0.160(0.026-0.976)$ & $\mathbf{0 . 0 5}$ \\
sinus involvement & & \\
\hline Cavernous sinus & $0.252(0.016-4.078)$ & 0.33 \\
involvement & & 0.26 \\
\hline Prior resection & $0.286(0.033-2.502)$ & $\mathbf{0 . 0 0 8}$ \\
\hline $\begin{array}{l}\text { Preoperative } \\
\text { embolization }\end{array}$ & $8.087(1.719-38.044)$ & \\
\hline
\end{tabular}

Superior sagittal sinus involvement made it more than ten times less likely that GTR would be achieved. Gross total resection was achieved in only 3 of $9(33 \%)$ patients invading the sinus, as compared to 31 of $49(63 \%)$ patients without sinus involvement. Furthermore, preoperative embolization made it ten times more likely that GTR would be achieved. For patients with supratentorial meningiomas, 27 of 37 (73\%) with pre-operative embolization achieved GTR, as compared to 7 of 21 (33\%) who did not achieve pre-operative embolization. In this study, supratentorial meningiomas were significantly easier to embolize than infrantentorial meningiomas $(p=0.007)$. Age $>45$ years and prior resection trended toward, but did not reach statistical significance.

Table 5: Multivariate associations with gross total resection following resection of large supratentorial meningiomas

\begin{tabular}{l|c|c}
\hline & \multicolumn{2}{|c}{ Multivariate } \\
\hline Variable & Odds Ratio (95\%CI) & p-value \\
\hline Age $>45$ & $0.947(0.894-1.003)$ & 0.06 \\
\hline Headache & $2.072(0.446-9.622)$ & 0.35 \\
\hline Prior resection & $0.141(0.015-1.370)$ & 0.09 \\
\hline Preoperative embolization & $10.492(1.961-56.135)$ & $\mathbf{0 . 0 0 6}$ \\
\hline Superior sagittal sinus & $0.077(0.010-0.571)$ & $\mathbf{0 . 0 1}$ \\
involvement & & \\
\hline
\end{tabular}




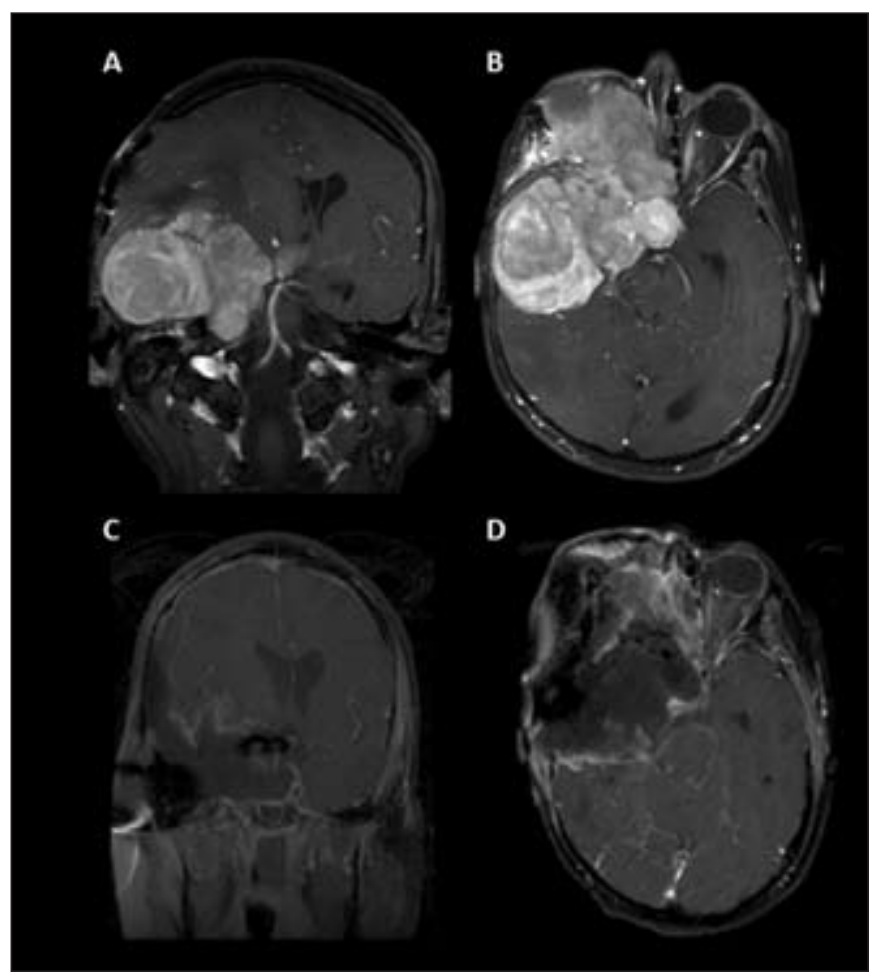

Figure: Pre-and post-operative T1-weighted MRI Images of a 27-yearold patient with a giant sphenoid wing meningioma that was successfully resected after receiving pre-operative embolization. A, pre-op coronal view. B, pre-op axial view. C, post-op coronal view. D, post-op axial view.

\section{Discussion}

This retrospective review of surgically treated large intracranial meningiomas $\geq 5 \mathrm{~cm}$ is the largest series to assess the feasibility of resecting these tumors, as well as the first to assess predictors of respectability. In this study, GTR can be achieved in the majority of cases with limited morbidity and mortality, where symptoms will likely improve and recurrences seldom occur. For all large meningiomas, age greater than 45 years and superior sagittal sinus involvement were independent negative predictors of GTR, while pre-operative embolization was a positive independent predictor of GTR. In fact, age $>45$ years and sagittal sinus involvement each made it eight and six times less likely, respectively, that GTR would be achieved, while preoperative embolization made it eight times more likely. In a separate analysis of only the supratentorial meningiomas, superior sagittal sinus involvement and pre-operative embolization remained independent predictors of GTR. Superior sagittal sinus involvement made it more than ten times less likely that GTR would be achieved, while preoperative embolization made it more than ten times more likely. Patient gender, duration of symptoms, presenting symptoms, imaging findings, tumor location, tumor size, and tumor pathology were not significantly associated with resectability.
Large intracranial meningiomas have been described in the literature for decades ${ }^{5,12,13}$. However, advances in neuroimaging have presumably allowed for the early detection and treatment of these lesions before they attain large $\operatorname{sizes}^{3}$. As a result, these tumors are relatively rare, and studies on large intracranial meningiomas are limited. The majority of these studies are limited to case reports $s^{6,12,14,15}$ and small case series ${ }^{4,5,16}$. Prior to this study, only two large series (> 20 cases) evaluated the resectability of large intracranial meningiomas ${ }^{7,17}$. Jiang et al described the feasibility of microsurgical excision in 56 large CPA meningiomas, but the size of these tumors was unknown ${ }^{17}$. Furthermore, Pomeranz et al demonstrated the feasibility of resecting cranial base tumors $(>4.5 \mathrm{~cm}), 23$ of which were meningiomas ${ }^{7}$. These studies, besides their smaller numbers, did not evaluate factors associated with attaining GTR of these lesions or quantitate other issues related to outcome such as duration of surgery, blood loss, or hospital stay.

For all large intracranial meningiomas, regardless of location, age greater than 45 years was an independent risk factor of resectability. This age range showed the greatest discrepancy in resectability. It may seem somewhat surprising that age was a predictive factor of respectability as this should have no influence on the local anatomy and physical characteristics of the tumor. However, age may reflect a surgeon's bias to be more aggressive with resection to minimize recurrence rates in younger patients because they tend to have a tendency to have longer survival times. Consequently, a more conservative approach is pursued with older patients for fear of producing unacceptable morbidity. This management philosophy in the elderly seems reasonable as there are other methods for controlling residual or recurrent disease such as with radiotherapy or radiosurgery. Nevertheless, there is an increasing incidence of meningiomas in the elderly ${ }^{18}$, and surgery has been associated with increased morbidity and mortality. Some series have reported morbidity rates as high as $45 \%$ in the elderly ${ }^{19-22}$. In this study, patients older than 45 years were less likely to have complete removal of their tumors. Therefore age, besides increasing the morbidity and mortality in patients with meningiomas, may also play a role in determining the surgeon's ability to resect these tumors.

Another factor independently associated with resectability of large intracranial meningiomas is superior sagittal sinus involvement. This was seen when analyzing all large meningiomas collectively, as well as separately analyzing the supratentorial large meningiomas. This association between sinus involvement and extent of resection is presumably due to the intrinsic relationship of the meningioma with the surrounding vascular structures, making GTR more difficult ${ }^{23,24}$. DiMeco et al reported that $8(7.4 \%)$ of 108 cases were Simpson Grade IV, where radical resection was especially not possible when the tumor completely obstructed the sinus and invaded the surrounding cortical veins ${ }^{11,24}$. Large intracranial meningiomas, as a result of their size, have an increased tendency to invade and obstruct the venous sinuses, making resection more difficult.

Preoperative embolization also independently predicted the ability to achieve GTR. This was seen in the entire cohort model, as well as the supratentorial model. Since its initial use in the 1970s, there have been several reports documenting its efficacy in reducing intra-operative blood loss and facilitating surgery by 
devascularizing the tumor ${ }^{25-27}$. Other studies have found no benefits ${ }^{28}$, and even noted complications including ischemia and hemorrhaging 29 . The embolization rates were highest for meningiomas involving the convexities, parasagittal, sphenoid wing, and falx in the present study, and may support the use of embolization specifically in these tumors to increase the likelihood that the surgeon may have a better chance to achieve a good resection. In this group we had one patient that had a small medial left occipital lobe infarct after embolization that was found in a subsequent preoperative MRI but the patient had no changes on exam. One potential reason why preoperative embolization may be independently associated with achieving a GTR in these lesions may be that tumor softening that occurs allows the margins of the tumor to be more easily manipulated, facilitating the dissection of the tumor-brain interface. This is something that may need to be explored further and not quite clear to the authors.

\section{Study limitations}

This study is inherently limited by its retrospective design, and, as a result, no direct causal relationships can be inferred from these data. Therefore, further prospective studies are needed to provide better data to guide clinical decision-making. We attempted to limit the retrospective bias associated with this approach by confirming the extent of resection with operative notes and post-operative neuroimaging, as well as by controlling for each variable found to show a statistical association or known to have a strong clinical relationship with our dependent variable. Furthermore, in order to reduce surgery-related differences, we only studied patient operated on at a single institution. It should be noted, however, that outcomes may be better at academic centers that have surgical teams devoted to treating complex tumors, since most of these operations require a sufficient amount of time. Additionally, we included tumors from different anatomical origins into the analysis. We sought to control for location by separately analyzing the supratentorial meningiomas. However, the sample size for the infratentorial meningiomas was too small to draw any meaningful conclusions. Studies with larger numbers are therefore needed to provide better data to guide clinical decision-making. Given the statistical control and a relatively precise outcome measure, we believe our findings offer useful insights into the management of patients undergoing large intracranial meningioma resection.

Series on large intracranial meningiomas are few and limited. This is primarily because they are relatively rare tumors, presumably as a result of advances in neuroimaging that have allowed for early detection of these lesions before the reach large sizes. As such, studies on the feasibility of resecting these large tumors, as well as the factors associated with GTR, remain largely unknown. In this series we found that age, superior sagittal sinus involvement and pre-operative embolization are important factors in determining the resection of these large intracranial tumors. This study shows that GTR can be achieved in the majority of cases with limited morbidity and mortality, where symptoms will likely improve and recurrences seldom occur.

\section{REFERENCES}

1. Drummond KJ, Zhu JJ, Black PM. Meningiomas: updating basic science, management, and outcome. Neurologist. 2004;10(3): 113-30.

2. Claus EB, Bondy ML, Schildkraut JM, Wiemels JL, Wrensch M, Black PM. Epidemiology of intracranial meningioma. Neurosurgery. 2005;57(6):1088-95; discussion 95.

3. Buhl R, Nabavi A, Wolff S, Hugo HH, Alfke K, Jansen O, et al. MR spectroscopy in patients with intracranial meningiomas. Neurol Res. 2007;29(1):43-6.

4. d'Avella D, Salpietro FM, Alafaci C, Tomasello F. Giant olfactory meningiomas: the pterional approach and its relevance for minimizing surgical morbidity. Skull Base Surg. 1999;9(1): 23-31.

5. Hirsh LF, Mancall EL. Giant meningiomas of the posterior fossa. JAMA. 1978;240(15):1626-7.

6. Lopez MJ, Olivares JL, Ramos F, Redondo JA, Ramon y Cajal S, Banzo J, et al. Giant meningioma in a 5-month-old infant. Childs Nerv Syst. 1988;4(2):112-5.

7. Pomeranz S, Umansky F, Elidan J, Ashkenazi E, Valarezo A, Shalit M. Giant cranial base tumours. Acta Neurochir (Wien). 1994; 129(3-4):121-6.

8. Simpson D. The recurrence of intracranial meningiomas after surgical treatment. J Neurol Neurosurg Psychiatry. 1957;20(1): 22-39.

9. Chun JY, McDermott MW, Lamborn KR, Wilson CB, Higashida R, Berger MS. Delayed surgical resection reduces intraoperative blood loss for embolized meningiomas. Neurosurgery. 2002; 50(6):1231-5; discussion 5-7.

10. Martin AJ, Cha S, Higashida RT, Cullen SP, Halbach V, Dowd CF, et al. Assessment of vasculature of meningiomas and the effects of embolization with intra-arterial MR perfusion imaging: a feasibility study. AJNR Am J Neuroradiol. 2007;28(9):1771-7.

11. Sindou MP, Alvernia JE. Results of attempted radical tumor removal and venous repair in 100 consecutive meningiomas involving the major dural sinuses. J Neurosurg. 2006;105(4): 514-25.

12. Cech DA, Leavens ME, Larson DL. Giant intracranial and extracranial meningioma: case report and review of the literature. Neurosurgery. 1982;11(5):694-7.

13. Cushing H, Eisenhardt L. Meningiomas: Their classification, regional behavior, life history, and surgical end results. Springfield, Illinois; 1938.

14. Alp H, Ceviker N, Baykaner K, Orbay T. Giant meningioma in a fourteen-month-old infant. Surg Neurol. 1985;24(1):77-9.

15. Benli K, Cataltepe O, Oge HK, Onol B. Giant congenital meningioma in a newborn. Childs Nerv Syst. 1990;6(8):462-4.

16. Sekhar LN, Swamy NK, Jaiswal V, Rubinstein E, Hirsch WE, Jr., Wright DC. Surgical excision of meningiomas involving the clivus: preoperative and intraoperative features as predictors of postoperative functional deterioration. J Neurosurg. 1994;81(6): 860-8.

17. Jiang YG, Xiang J, Wen F, Zhang LY. Microsurgical excision of the large or giant cerebellopontine angle meningioma. Minim Invasive Neurosurg. 2006;49(1):43-8.

18. Roser F, Ebner FH, Ritz R, Samii M, Tatagiba MS, Nakamura M. Management of skull based meningiomas in the elderly patient. J Clin Neurosci. 2007;14(3):224-8.

19. Papo I. Intracranial meningiomas in the elderly in the CT scan era. Acta Neurochir (Wien). 1983;67(3-4):195-204.

20. Awad IA, Kalfas I, Hahn JF, Little JR. Intracranial meningiomas in the aged: surgical outcome in the era of computed tomography. Neurosurgery. 1989;24(4):557-60.

21. Cornu P, Chatellier G, Dagreou F, Clemenceau S, Foncin JF, Rivierez M, et al. Intracranial meningiomas in elderly patients. Postoperative morbidity and mortality. Factors predictive of outcome. Acta Neurochir (Wien). 1990;102(3-4):98-102.

22. Mastronardi L, Ferrante L, Qasho R, Ferrari V, Tatarelli R, Fortuna A. Intracranial meningiomas in the 9th decade of life: a retrospective study of 17 surgical cases. Neurosurgery. 1995;36 (2):270-4 
23. Ayerbe J, Lobato RD, de la Cruz J, Alday R, Rivas JJ, Gomez PA, et al. Risk factors predicting recurrence in patients operated on for intracranial meningioma. A multivariate analysis. Acta Neurochir (Wien). 1999;141(9):921-32.

24. DiMeco F, Li KW, Casali C, Ciceri E, Giombini S, Filippini G, et al. Meningiomas invading the superior sagittal sinus: surgical experience in 108 cases. Neurosurgery. 2004;55(6):1263-72; discussion 72-4.

25. Hieshima GB, Everhart FR, Mehringer CM, Tsai F, Hasso AH, Grinnell VS, et al. Preoperative embolization of meningiomas. Surg Neurol. 1980;14(2):119-27.
26. Manelfe C, Lasjaunias P, Ruscalleda J. Preoperative embolization of intracranial meningiomas. AJNR Am J Neuroradiol. 1986;7 (5):963-72.

27. Richter HP, Schachenmayr W. Preoperative embolization of intracranial meningiomas. Neurosurgery. 1983;13(3):261-8.

28. Bendszus M, Rao G, Burger R, Schaller C, Scheinemann K, Warmuth-Metz $\mathrm{M}$, et al. Is there a benefit of preoperative meningioma embolization? Neurosurgery. 2000;47(6):1306-11; discussion 11-2.

29. Bendszus M, Monoranu CM, Schutz A, Nolte I, Vince GH, Solymosi L. Neurologic complications after particle embolization of intracranial meningiomas. AJNR Am J Neuroradiol. 2005;26(6):1413-9. 